\title{
THE INFLUENCE OF BRAND IMAGE ON THE SELECTION AND PREFERENCE OF UNIVERSITIES OF TECHNOLOGY
}

\author{
Cleopatra Moipone Matli ${ }^{1}$ \\ Tshepo Tlapana $\bowtie$ \\ Department of Corporate Communications \& Marketing \\ Walter Sisulu University \\ East London, South Africa, 5200 \\ ttlapana@wsu.ac.za
}

Raymond Hawkins-Mofokeng ${ }^{1}$

${ }^{1}$ Department of Marketing \& Retail

Durban University of Technology

Durban, South Africa, 4000

$\bowtie$ Corresponding author

\begin{abstract}
The research focuses on the factors that influence student brand preferences for Universities of Technology in KwaZulu-Natal. Brand preference is a marketing indicator that reflects a brand's market position. This indicator reveals whether consumers prefer one brand in the same category over another. Developing brand preference as a long-term strategy assists in the development of brand equity, which builds a brand's popularity and market domination in comparison to competitors. The primary goals of this research were to: investigate the most influential factors, influencing student brand choices; and identify traits that students in KwaZulu-Natal consider to be critical in the choosing of a University of Technology (UoT). The study also aimed to recommend strategies to improve service delivery in Universities of Technology. An exploratory study was carried out using a quantitative research approach, wherein questionnaires were administered to 500 DUT and MUT first-year students at the KwaZulu-Natal Universities of Technology and analysed using statistical packages for social sciences (SPSS). The study found that factors, such as investments in brand awareness and brand image, and service delivery influenced participants' choice and willingness to recommend their institutions to potential students. As a result, the report proposes that UoTs prioritize branding efforts as a means of guaranteeing institutional profitability, viability, and customer relationship management.
\end{abstract}

Keywords: types of universities, student brand preferences, university service quality, student decision making.

DOI: $10.21303 / 2504-5571.2021 .002065$

\section{Introduction}

Many theorists have not explored the influence of brand image on South African Universities of technology. As a result, the study aims to discover which brand image attributes first-year students find most influential when choosing a University of Technology (UoT). This study also tries to understand why students choose different institutions and how Universities have made this a key concern. As a result, institutions in South Africa and around the world have decided to diversify their marketing efforts. Between 1990 and 2000, it was discovered that social media, among other platforms, played a significant effect in millennials' decisions, particularly when it came to choosing a University [1], and as such Universities have so attempted to reinvent themselves by increasing their visibility on social media and other prominent digital channels [2].

Private institutions (such as Damelin, Varsity College, and Monash University) appear to be the most notable players in the South African higher education field to participate in full-fledged direct marketing activities [3]. In the literature, these are referred to as "for-profit institutions," and they are essentially private enterprises that operate as a company in the higher education sector. These institutions do not receive government support, nor do they have the same social duties as UoTs. As a result, these organizations have been obliged to deal with market phenomena from the 
beginning. Nonetheless, some have prospered in the South African higher education landscape and are beginning to provide serious competition to well-established public institutions. The competitive challenge they provide may have an opposite effect on Universities of technology, such as Mangosuthu University of Technology (MUT), which has been underperforming in terms of public relations [4]. In contrast to MUT, the Durban University of Technology (DUT) has made significant efforts through its Cooperate Affairs section to build a brand image and brand awareness as an agenda to improve its image locally and internationally [5]. However, privately run universities, such as Damelin, have utilized more proactive measures to develop an image and awareness among potential students.

\section{1. Types of Universities}

The higher education hierarchy in South Africa (SA) is constructed and understood through a variety of narratives. In South Africa, different Higher Education Institutions (HEIs) provide different qualifications at various levels. According to [6], the overall changes that this sector has endured have prompted its distinctive past and legacy to be expressed from a variety of perspectives. Firstly, there are Traditional Universities, which are institutions of higher education and research that offer academic degrees in a range of fields. Secondly, there are Universities of Technology (UoTs) that provide nearly identical academic degrees in a variety of subjects as traditional Universities. However, UoT qualifications provide practice-based learning in the disciplines of technology as well as vocationally oriented Diplomas and Degrees in engineering and business [7].

Conversely, private colleges, on the other hand, are self-governing institutions with their own set of rules and missions and are funded privately. Private institutions in South Africa, such as the Vega School of Branding, City Varsity, Rosebank College, and the Design School Southern Africa, are considerably smaller than public Universities, with the majority of these institutions, specialising in specialist programs. Fine arts colleges teach students how to turn into specialised artists and inventors, while others are devoted to technology, commercial, or marketing. Then there are Further Education and Training (FET) colleges, which are institutions that have been formed, listed, and operate under the supervision of the Department of Higher Education and Training (DHET). Their overarching goal is to provide vocational or work-related preparation in a certain subject, with students, selecting from a wide range of programs based on their abilities and career path [8]. Should students desire to further their studies in the same field at the university level, the college may perhaps have provided the contextual training and preparation necessary for entry.

General education encompasses the first nine years of secondary school education. As a result, FET includes the final three years of education or completion of a similar certificate or certification at a practical college or educational institute, whereas higher education includes university-level scholarships, which are primarily intellectual. The government contributes four billion rands to these FETs each year [8]. The Further Education and Training Colleges Act 16 of 2006 mandated that private colleges register with the Department of Higher Education to offer authorised FET programs.

\section{2. Factors influencing Student Brand Preference}

Studies have shown that there are a number of variables that students will consider when selecting a University to study at. These elements are influenced by but are not limited to, the University's image. According to [9], data was obtained among undergraduate students at a Taiwanese institution. $94 \%$ of the total number of pupils chose the criterion valid school image, while $89 \%$ chose the criterion school. In contrast, [10] suggested in a different study that sensory thresholds, perceptual selection, and personal selection factors all play a role in the university choosing process. Other considerations include the cost, location, or proximity to home and the quality of academic personnel.

According to [11] the primary selection criteria for students include a nice environment, strong academic standards, course availability, good faculty, and high standards. The authors also highlighted financial aid, peer influence, unique programs, the size of the school, location, sporting facilities, and social activities as major criteria in selecting an educational institution. [12] also 
accept that factors that have the biggest beneficial influence on student University choice include teaching quality, prestige, infrastructure, library, computer facilities, location, quality of the curricula, scientific research quality, administrative support, extra-curricular factors (sports, leisure, canteens, etc.) and the availability of exchange programs with foreign Universities are all factors to consider.

In an environment where students are viewed as clients, institutions must adapt and design strategies to maintain and increase their competitive edge based on their unique traits [13]. Furthermore, institutions must actively and consistently disclose these advantages to their suitable investors. According to [14], Universities value corporate identity as a powerful source of competitive advantage.

\subsection{University Service Quality}

According to [15], University service quality refers to the total approach toward providing a service and meeting student expectations. Physical quality, interaction quality, and organisational corporate quality can all be used to define University service quality. The tangible aspects of services influence student impressions of University personnel behavior and play a key effect in student perceptions of University service quality. According to [16], the most widely used definition of University service quality is the amount, to which a service satisfies student needs; it also includes a comparison of student expectations with their perceptions of actual University service performance.

University Service quality is sometimes defined as the difference between service expectations and actual performance perceptions. In today's competitive market, the function of service quality is widely recognised as a critical aspect in the success and survival of a University. Any drop in student satisfaction as a result of poor service quality would be cause for concern. As a result of competitive trends that have raised expectations, students are becoming more aware of higher service requirements. To attain service excellence, Universities must strive for zero defections, retaining every student that the University can profitably serve [17]. [18] further adds that one of the essential success criteria, influencing an organization's competitiveness, is service quality. The University can distinguish itself from competitors by delivering high-quality services.

According to [19], University service quality has become a crucial differentiator and the most potent competitive weapon that many leading Universities have. Leading Universities seek to provide exceptional service to gain student loyalty; thus, a University's long-term performance in a market is largely decided by its ability to expand and retain a big and loyal student population. Although student loyalty is critical to institution survival, the relationship between perceived service quality and student loyalty has remained unexplored.

\section{4. Student Decision Making}

A brand has a stronger influence on student decision-making, according to [20]. Universities manage their brands by catering to the needs and desires of their students. Students are intrigued not only by brands that reflect their attitudes and values, but also by trends and changes in their lifestyles. As a result, the brand has a bigger influence on University selection. Understanding the decision-making processes of learners can offer HEIs a vision into their path as well as the growth of a unique marketing plan. Consequently, an understanding of the comparative rank of optimal aspects as a choice in learners' assortment procedures can enhance the modification of directed marketing plans. This decision-making process and what it involves is illustrated in Fig. 1.

In the higher education sector, it is simply assumed, that students go through these stages before deciding on a University or university of technology. Students in this study were aware that they searched for information about the institutions, compared them to the alternatives, then decided as to which institution they will study at and had to sit and revisit their process after considering everything else and agree or disagree with their decision. According to [22], understanding the university selection process is difficult. The process of selecting a University is a significant and complex decision for a student, not just in monetary terms, but also because it entails a long-term decision that influences student life. This decision may have an impact on the student's future job, friendships, future residence, and personal fulfillment. 


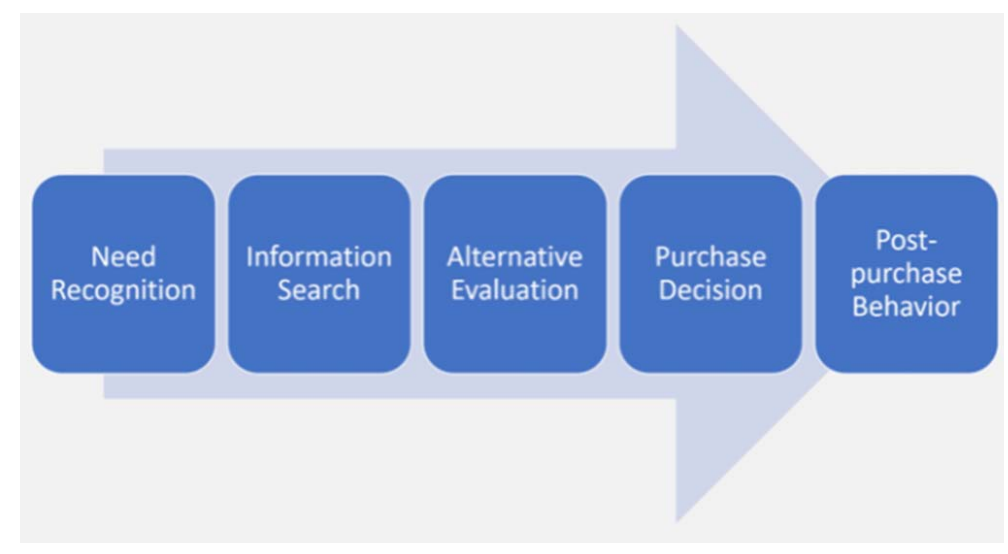

\section{Materials and Methods}

Fig. 1. Decision-making process. Source: [21]

The study was both explanatory and quantitative. An explanatory study was conducted in order to acquire a better understanding of the research problem. Students from Universities of technology in the KwaZulu-Natal province made up the study population. The current study followed the ethical norms, enforced by the Ethics Committees of both DUT and MUT, and the researchers got authorization from the appropriate committees. All study participants provided voluntary and informed consent.

The table below shows the total number of first-year students, enrolled at both DUT and MUT. These figures were used to estimate the number of students who would be available to complete the surveys. Table 1 contains further information on the demographic, target population, and sample size.

Table 1

Student enrolments at UoTs

\begin{tabular}{cccc|}
\hline Population & Target population & Population of first-year students & Sample size \\
\hline UoTs in KZN & - & 9800 & 500 \\
DUT & First-year students - Durban & 6000 & 300 \\
MUT & First-year students & 3800 & 200
\end{tabular}

Source: DUT and MUT websites, enrolment figures 2018

According to [23], sample sizes of more than 30 and less than 500 are sufficient for most investigations. This study has a population of 9800 people and a sample of 500 people due to the multiple variables to be investigated. A study with 9000 to 10000 participants should have a sample size of 368 to 370 people [23] however, because the researcher allowed for non-response owing to the nature of the sample, a sample size of 500 was determined to be adequate. The study employed the non-probability sampling technique and quota sampling, which selects a sample of respondents with the same proportions of characteristics as the entire population, but not on an ad hoc basis. As a result, the study concentrated on first-year students from the two Universities listed, who were picked in equal numbers based on race and gender.

This study employed a survey method, with self-administered questionnaires, serving as data collection tools. The current study employed a "self-delivery" technique by the researcher to first-year students during the First Years' Orientation and Registration periods, with the support of professional field workers to the study's participants. This technique was chosen because it frequently improves response rate; also, the researcher was able to clarify questions that respondents did not fully comprehend to determine which questions needed rephrasing and/or were to be removed from the study. The surveys were collected as soon as each responder completed them. This approach reduces the possibility of losing questionnaire copies or obtaining non-responses [24]. 
Cronbach's alpha, a measure of internal consistency or how closely linked a group of objects is, was used to analyze the Reliability assessment for brand Image. This is acknowledged as a gauge of scale dependability.

\section{Result}

Table 2 illustrates the age groups of the respondents based on their UoTs.

The Fisher exact tests, as demonstrated by the degree of significance, show that the respondents' age group differs significantly $(\mathrm{P}<0.05)$. For example, it can be seen, that respondents aged 18 to 21 make up the majority for both the DUT (69.9\%) and the MUT (71.1\%). Respondents over the age of 25 had the lowest representation for DUT (3.0\%) and MUT (2.9\%). The low presence of respondents above the age of 25 could be attributed to the South African education system, in which students pass matric and enroll in Higher Education Institutions between the ages of 18 and 19. This could also explain why respondents at both UoTs were mostly between the ages of 18 and 21.

Table 2

Age of respondents

\begin{tabular}{|c|c|c|c|c|c|}
\hline & \multirow{2}{*}{ Age group } & & \multicolumn{2}{|c|}{ University of Technology } & \multirow{2}{*}{ Total } \\
\hline & & & DUT & MUT & \\
\hline \multirow{11}{*}{ Age } & \multirow{2}{*}{ Below 18} & Count & 36 & 5 & 41 \\
\hline & & $\%$ within UoT & $12.2 \%$ & $2.5 \%$ & $8.2 \%$ \\
\hline & \multirow{2}{*}{$18-21$} & Count & 207 & 145 & 352 \\
\hline & & $\%$ within UoT & $69.9 \%$ & $71.1 \%$ & $70.4 \%$ \\
\hline & \multirow{2}{*}{$22-25$} & Count & 41 & 48 & 89 \\
\hline & & $\%$ within UoT & $13.9 \%$ & $23.5 \%$ & $17.8 \%$ \\
\hline & \multirow{2}{*}{ Above 25} & Count & 9 & 6 & 15 \\
\hline & & $\%$ within UoT & $3.0 \%$ & $2.9 \%$ & $3.0 \%$ \\
\hline & \multirow{3}{*}{ Total } & Count & 296 & 204 & 500 \\
\hline & & $\%$ within UoT & $100.0 \%$ & $100.0 \%$ & $100.0 \%$ \\
\hline & & $\%$ of Total & $59.2 \%$ & $40.8 \%$ & $100.0 \%$ \\
\hline
\end{tabular}

Fisher Exact test $=0.000$

Given that both UoTs (DUT and MUT) are located in KwaZulu-Natal, it was imperative to ascertain whether all respondents were residents of the province. The Fisher exact test, as indicated in Table 3, found no significant difference in respondents' residence at the two UoTs.

However, DUT boasts $83.4 \%$ of its students from the KwaZulu-Natal province, while MUT has $88.2 \%$. DUT, on the other hand, has $15.9 \%$ of students from outside the province, while MUT has $11.8 \%$. It is safe to infer that the majority of students in Kwazulu-Natal UoTs are from the province, with only a minor proportion from the rest of the country and beyond.

Table 3

KwaZulu-Natal residential status of the respondents

\begin{tabular}{|c|c|c|c|c|c|}
\hline \multirow{2}{*}{\multicolumn{3}{|c|}{ Residence within KwaZulu-Natal }} & \multicolumn{2}{|c|}{ University of Technology } & \multirow{2}{*}{ Total } \\
\hline & & & DUT & MUT & \\
\hline \multirow{4}{*}{ Original Residence KZN } & \multirow{2}{*}{ Yes } & Count & 247 & 180 & 427 \\
\hline & & $\%$ within UoT & $83.4 \%$ & $88.2 \%$ & $85.4 \%$ \\
\hline & \multirow{2}{*}{ No } & Count & 47 & 24 & 71 \\
\hline & & $\%$ within UoT & $15.9 \%$ & $11.8 \%$ & $14.2 \%$ \\
\hline \multirow{3}{*}{ Total } & & Count & 296 & 204 & 500 \\
\hline & & $\%$ within UoT & $100.0 \%$ & $100.0 \%$ & $100.0 \%$ \\
\hline & & $\%$ of Total & $59.2 \%$ & $40.8 \%$ & $100.0 \%$ \\
\hline
\end{tabular}

Fig. 2 depicts the respondents' distribution pattern. 
Among the DUT respondents who reside out of the KwaZulu-Natal province, $34.7 \%$ reside in the Eastern Cape, followed by those who reside in Mpumalanga, and other locations outside the listed provinces (18.4\%). For the MUT respondents, the majority (62.9\%) reside in the Eastern Cape, followed by those, residing in the Free State (11.1\%). In addition, while $4.0 \%$ of the respondents from the DUT reside in North West, no respondents from MUT resided in this province.

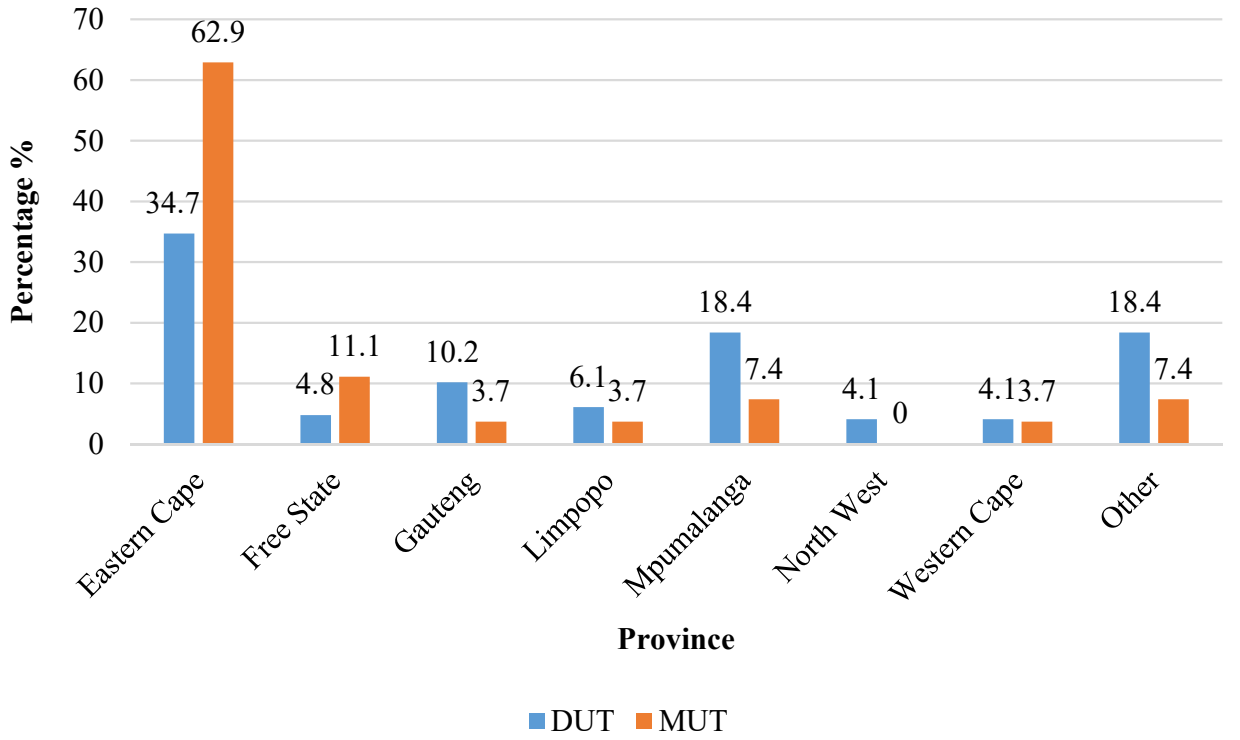

Fig. 2. Respondents' residential province outside KwaZulu-Natal

Table 4 presents the dependability evaluation for the part on brand image. The subsections brand promise $(\alpha 0.918)$ and brand voice $(\alpha 0.915)$ both get an outstanding Cronbach alpha score. Similarly, the subsections target audience $(\alpha 0.800)$, brand positioning $(\alpha 0.867)$, brand values $(\alpha$ 0.832), and brand image ( $\alpha$ 0.856) have a decent Cronbach alpha score, whereas the subsection brand perception $(\alpha 0.751)$ has a Cronbach alpha score that is higher than the acceptable value. Overall, based on the excellent alpha score $(\alpha 0.965)$, it can be deduced, that the instrument and items, used to measure brand image, are dependable, hence supporting its usage in data collecting.

Table 4

Reliability assessment for brand Image

\begin{tabular}{ccccc}
\hline Focus Area & Section C & Subsection & N of Items & Cronbach's Alpha \\
\hline $10.1-10.14$ & & Brand image & 14 & 0.856 \\
$11.1 \mathrm{a}-11.1 \mathrm{e}$ & Target Audience & 5 & 0.800 \\
$11.2 \mathrm{a}-11.2 \mathrm{j}$ & Brand Promise & 10 & 0.918 \\
$11.3 \mathrm{a}-11.3 \mathrm{c}$ & \multirow{2}{*}{ Brand image } & Brand Perception & 3 & 0.751 \\
$11.4 \mathrm{a}-11.4 \mathrm{~d}$ & Brand Values & 4 & 0.832 \\
$11.5 \mathrm{a}-11.5 \mathrm{i}$ & Brand Voice & 9 & 0.915 \\
$11.6 \mathrm{a}-11.6 \mathrm{e}$ & & Brand Positioning & 5 & 0.867 \\
Total & - & 50 & 0.965
\end{tabular}

As indicated by the level of significance, the One-Sample T-test, highlighted in Table 5, indicated that the extent, to which the respondents agree or disagree with the statements on the DUT brand, was significantly different $(\mathrm{p}<0.01)$. This suggests that there were differences between the way respondents scored (strongly disagree, disagree, neutral, agree, and strongly agree). It was observed, that more of the respondents $(62.5 \%$ ) agreed (agree $=40.9 \%$; strongly agree $=21.6 \%$ ) that 'the DUT brand sends clear communication messages to me' (Q9.1). Similarly, there was high $(56.7 \%$ ) positive agreement (agree $=41.2 \%$; strongly agree $=15.5 \%$ ), noted for the statement (Q9.2) that the DUT brand is communicated consistently. Concerning the statement that the 
DUT brand reflects the UoT's vision (Q9.3), half of the respondents $(50.4 \%$ ) agreed (agree=33.8 \%; strongly agree $=16.6 \%$ ), while $35.8 \%$ were unsure. More so, it emerged, that $68.5 \%$ of the respondents positively agreed (agree $=32.4 \%$; strongly agree $=36.1 \%$ ) that the DUT brand provides all students with equal access to learning opportunities (Q9.4).

Table 5

Respondents extent of agreement on the DUT brand

\begin{tabular}{|c|c|c|c|c|c|c|c|c|c|}
\hline \multirow{2}{*}{ Statement } & \multirow{2}{*}{ No } & \multicolumn{5}{|c|}{ Likert scale } & \multirow{2}{*}{ Mean } & \multirow{2}{*}{ Std. } & \multirow{2}{*}{$P$-value } \\
\hline & & SD & D & $\mathbf{N}$ & $\mathbf{A}$ & $\mathbf{S A}$ & & & \\
\hline Q9.1 & 296 & $9.8 \%$ & $6.1 \%$ & $21.6 \%$ & $40.9 \% \%$ & $21.6 \% \%$ & 3.58 & 1.179 & $0.000^{* *}$ \\
\hline Q9.2 & 296 & $8.1 \%$ & $6.4 \%$ & $28.7 \%$ & $41.2 \%$ & $15.5 \%$ & 3.50 & 1.086 & 0.000 \\
\hline Q9.3 & 296 & $11.1 \%$ & $2.7 \%$ & $35.8 \%$ & $33.8 \%$ & $16.6 \%$ & 3.42 & 1.141 & 0.000 \\
\hline Q9.4 & 296 & $7.1 \%$ & $5.4 \%$ & $18.9 \%$ & $32.4 \%$ & $36.1 \%$ & 3.85 & 1.178 & 0.000 \\
\hline Q9.5 & 296 & $7.1 \%$ & $3.4 \%$ & $30.1 \%$ & $40.2 \%$ & $19.3 \%$ & 3.61 & 1.058 & 0.000 \\
\hline Q9.6 & 296 & $8.1 \%$ & $2.7 \%$ & $17.6 \%$ & $38.9 \%$ & $32.8 \%$ & 3.85 & 1.151 & 0.000 \\
\hline Q9.7 & 296 & $6.4 \%$ & $3.0 \%$ & $16.9 \%$ & $36.1 \%$ & $37.5 \%$ & 3.95 & 1.116 & 0.000 \\
\hline Q9.8 & 296 & $8.4 \%$ & $4.1 \%$ & $28.7 \%$ & $39.2 \%$ & $19.6 \%$ & 3.57 & 1.108 & 0.000 \\
\hline Q9.9 & 296 & $10.5 \%$ & $5.7 \%$ & $37.8 \%$ & $33.1 \%$ & $12.8 \%$ & 3.32 & 1.105 & 0.000 \\
\hline Q9.10 & 296 & $9.5 \%$ & $5.1 \%$ & $37.5 \%$ & $36.8 \%$ & $11.1 \%$ & 3.35 & 1.060 & 0.000 \\
\hline Q9.11 & 296 & $8.8 \%$ & $6.4 \%$ & $36.1 \%$ & $36.8 \%$ & $11.8 \%$ & 3.36 & 1.062 & 0.000 \\
\hline Q9.12 & 296 & $8.4 \%$ & $3.4 \%$ & $34.5 \%$ & $40.5 \%$ & $13.2 \%$ & 3.47 & 1.044 & 0.000 \\
\hline Q9.13 & 296 & $8.8 \%$ & $3.4 \%$ & $29.4 \%$ & $34.5 \%$ & $24.0 \%$ & 3.61 & 1.147 & 0.000 \\
\hline Q9.14 & 296 & $8.8 \%$ & $2.7 \%$ & $23.3 \%$ & $42.2 \%$ & $23.0 \%$ & 3.68 & 1.124 & 0.000 \\
\hline Q9.15 & 296 & $7.8 \%$ & $2.0 \%$ & $16.2 \%$ & $46.3 \%$ & $27.7 \%$ & 3.84 & 1.095 & 0.000 \\
\hline Q9.16 & 296 & $8.1 \%$ & $2.4 \%$ & $25.7 \%$ & $38.9 \%$ & $25.0 \%$ & 3.70 & 1.117 & 0.000 \\
\hline
\end{tabular}

A Likert scale of $1=$ strongly disagree (SD), 2=disagree (D), 3=neutral, 4=agree (A), $5=$ strongly agree (SA) was used.

** Level of significance $p<0.01$ (2-tailed).

Given the high number of respondents who indicated that the DUT brands provide students with equal access, it was predictable, that a high proportion of them (59.5\%) were in agreement (agree $=40.2 \%$; strongly agree $=19.3 \%$ ) that the DUT brands reflect the UoTs mission (Q9.5). Furthermore, $71.7 \%$ of the participants agreed (agree $=38.9 \%$; strongly agree $=32.8 \%$ ) that the DUT brand reflects their educational needs (Q9.6). It also emerged, that $73.6 \%$ of the respondents agreed (agree $=36.1 \%$; strongly agree $=37.5 \%$ ) that the DUT brand is well recognised nationally (Q9.7). More so, $58.8 \%$ of the respondents agreed (agree $=39.2 \%$; strongly agree $=19.6 \%$ ) that the DUT brand reflects the visual expression of the UoT (Q9.8). Similarly, a high proportion (70.9\%) of the respondents agreed (agree $=37.8 \%$; strongly agree $=33.1 \%$ ) that the DUT brand reflects engagement with all stakeholders (Q9.9).

Although $37.8 \%$ of the respondents were neutral, it was, however, noted that nearly half of the respondents $48.6 \%$ agreed (agree $=36.8 \%$; strongly agree $=11.8 \%$ ) that the DUT brand is a verbal expression of the UoT (Q9.10). Similarly, it was observed, that a high number (36.1\%) appear to be neutral, while $48.8 \%$ agreed (agree $=36.8 \%$; strongly agree $=11.8 \%$ ) that the DUT brand fulfills specific stakeholders' needs (Q9.11). Moreover, more than half of the respondents, $53.7 \%$ agreed (agree $=40.5 \%$; strongly agree $=13.2 \%$ ) that the DUT brand is well accepted by stakeholders (Q9.12).

Furthermore, $58.5 \%$ of the respondents strongly affirmed (agree $=34.5 \%$; strongly agree $=24.0 \%$ ) that the DUT/MUT brand is well recognised internationally (Q9.13). Given the percentage of respondents who acknowledged the international brand of the DUT, it was highly expected, that a high proportion (65.2\%) of the respondents positive agreed (agree $=42.2 \%$; strongly agree $=23.0 \%$ ) that the DUT brand creates high levels of awareness (Q9.14). It is important to note, that the majority $(74.0 \%$ ) of the respondents indicated (agree $=46.3 \%$; strongly agree $=27.7 \%$ ) that the DUT brand has real meaning or relevance to them (Q9.15). Consequently, it was no surprise, 
that $63.9 \%$ of the respondents agreed (agree $=38.9 \%$; strongly agree $=25.0 \%$ ) that the DUT brand identity is strongly established in the minds of the stakeholders.

As indicated by the level of significance, the One-Sample T-test, highlighted in Table 6, indicates that the extent, to which the respondents agree or disagree with the statements on the MUT brand, was significantly different $(P<0.01)$. In terms of the statement the MUT brand sends clear communication messages to me (Q9.1), it was observed, that more $(74.5 \%)$ of the respondents were in agreement (agree $=46.6 \%$; strongly agree $=27.9 \%$ ). Equally, $65.7 \%$ of the respondents positively agreed (agree $=48.5 \%$; strongly agree $=17.2 \%$ ) that the MUT brand is communicated in a consistent manner (Q9.2).

Table 6

Respondents extent of agreement on the MUT brand

\begin{tabular}{|c|c|c|c|c|c|c|c|c|c|}
\hline \multirow{2}{*}{ Statement } & \multirow{2}{*}{ No } & \multicolumn{5}{|c|}{ Likert scale } & \multirow{2}{*}{ Mean } & \multirow{2}{*}{ Std. } & \multirow{2}{*}{$P$-value } \\
\hline & & SD & D & $\mathbf{N}$ & A & SA & & & \\
\hline Q9.1 & 204 & $1.0 \%$ & $3.4 \%$ & $21.1 \%$ & $46.6 \%$ & $27.9 \%$ & 3.97 & 0.848 & $0.000 * *$ \\
\hline Q9.2 & 204 & $1.0 \%$ & $5.4 \%$ & $27.9 \%$ & $48.5 \%$ & $17.2 \%$ & 3.75 & 0.836 & 0.000 \\
\hline Q9.3 & 204 & $1.0 \%$ & $5.4 \%$ & $41.2 \%$ & $38.2 \%$ & $14.2 \%$ & 3.59 & 0.834 & 0.000 \\
\hline Q9.4 & 204 & $1.0 \%$ & $9.8 \%$ & $14.7 \%$ & $35.8 \%$ & $38.7 \%$ & 4.01 & 1.010 & 0.000 \\
\hline Q9.5 & 204 & $1.0 \%$ & $5.9 \%$ & $33.8 \%$ & $45.1 \%$ & $14.2 \%$ & 3.66 & 0.830 & 0.000 \\
\hline Q9.6 & 204 & $0.0 \%$ & $5.9 \%$ & $19.1 \%$ & $45.6 \%$ & $29.4 \%$ & 3.99 & 0.851 & 0.000 \\
\hline Q9.7 & 204 & $0.0 \%$ & $2.9 \%$ & $20.1 \%$ & $40.7 \%$ & $36.3 \%$ & 4.10 & 0.821 & 0.000 \\
\hline Q9.8 & 204 & $1.0 \%$ & $7.8 \%$ & $34.8 \%$ & $45.1 \%$ & $11.3 \%$ & 3.58 & 0.830 & 0.000 \\
\hline Q9.9 & 204 & $2.9 \%$ & $6.4 \%$ & $48.5 \%$ & $34.8 \%$ & $7.4 \%$ & 3.37 & 0.830 & 0.000 \\
\hline Q9.10 & 204 & $2.5 \%$ & $7.4 \%$ & $41.7 \%$ & $37.7 \%$ & $10.8 \%$ & 3.47 & 0.873 & 0.000 \\
\hline Q9.11 & 204 & $1.5 \%$ & $7.4 \%$ & $46.6 \%$ & $38.7 \%$ & $5.9 \%$ & 3.40 & 0.772 & 0.000 \\
\hline Q9.12 & 204 & $1.5 \%$ & $4.4 \%$ & $40.7 \%$ & $40.7 \%$ & $12.7 \%$ & 3.59 & 0.823 & 0.000 \\
\hline Q9.13 & 204 & $2.0 \%$ & $9.3 \%$ & $28.9 \%$ & $32.8 \%$ & $27.0 \%$ & 3.74 & 1.021 & 0.000 \\
\hline Q9.14 & 204 & $1.5 \%$ & $2.9 \%$ & $21.6 \%$ & $45.6 \%$ & $28.4 \%$ & 3.97 & 0.867 & 0.000 \\
\hline Q9.15 & 204 & $1.0 \%$ & $4.9 \%$ & $19.1 \%$ & $45.6 \%$ & $29.4 \%$ & 3.98 & 0.879 & 0.000 \\
\hline Q9.16 & 204 & $2.0 \%$ & $0.5 \%$ & $32.4 \%$ & $47.1 \%$ & $18.1 \%$ & 3.79 & 0.812 & 0.000 \\
\hline
\end{tabular}

A Likert scale of $1=$ strongly disagree (SD), 2=disagree (D), 3=neutral, $4=$ agree (A), 5=strongly agree (SA) was used.

** Level of significance $p<0.01$ (2-tailed).

For the statement that the MUT brand reflects the UoT's vision (Q9.3), it was observed, that $41.2 \%$ were unsure, while more than half (52.4\%) of the respondents agreed (agree $=38.2 \%$; strongly agree $=14.2 \%)$. Further to this, it emerged, that a high proportion $(75.5 \%)$ of the respondents positively agreed (agree $=35.8 \%$; strongly agree $=39.7 \%$ ) that the MUT brand provides all students with equal access to learning opportunities (Q9.4). Mostly, $59.3 \%$ of the respondents agreed (agree $=45.1 \%$; strongly agree $=14.2 \%$ ) that the MUT brands reflect the UoTs mission (Q9.5). More so, a majority of the respondents (75\%) indicated that the MUT brand reflects their educational needs (Q9.6).

Furthermore, a good percentage ( $77 \%$ ) of the respondents agreed (agree $=40.7 \%$; strongly agree $=36.3 \%$ ) that the MUT brand is well recognised nationally (Q9.7). Nonetheless, $34.8 \%$ of them appeared to be unsure whether the MUT brand reflects the visual expression of the UoT (Q9.8). This notwithstanding, it emerged, that more than half (56.4\%) of the respondents consider the MUT brand to reflect the visual expression of the UoT (agree $=45.1 \%$; strongly agree $=11.3 \%$ ). It can be concluded, that nearly half (48.5\%) of the respondents remain neutral on whether the MUT brand reflects engagement with all stakeholders (Q9.9).

Moreover, $41.7 \%$ of the respondents were neutral that the DUT/MUT brand is a verbal expression of the UoT (Q9.10). Similarly, it was observed, that $46.6 \%$ also appear to be neutral, while $44.0 \%$ agreed (agree $=38.7 \%$; strongly agree $=5.9 \%$ ) that the DUT/MUT brand fulfills specific 
stakeholders' needs (Q9.11). Nevertheless, $40.7 \%$ of the respondents appear to be unsure (neutral) regarding the MUT brand acceptability by stakeholders, while more than half (53.4\%) of them agreed (agree $=40.7 \%$; strongly agree $=12.7 \%$ ) that the brand is well accepted by stakeholders (Q9.12).

Despite the large number that appeared neutral on the acceptability of the MUT brand, it was found, that $59.8 \%$ of the respondents agreed (agree $=32.8 \%$; strongly agree $=27 \%$ ) that the MUT brand is well recognised internationally (Q9.13). Significantly, a high proportion (74\%) of the respondents agreed (agree $=45.6 \%$; strongly agree $=28.4 \%$ ) that the MUT brand creates high levels of awareness (Q9.14). Similarly, $75 \%$ of the respondents claimed (agree=45.6 \%; strongly agree $=29.4 \%$ ) that the DUT/MUT brand has real meaning or relevance to them (Q9.15). Given the relevance of the MUT brand in the minds of the students, it was not a surprise, that $65.2 \%$ of the respondents agreed (agree $=47.1 \%$; strongly agree $=18.1 \%$ ) that the DUT/MUT brand identity is strongly established in the minds of the stakeholders.

Given the preceding scoring pattern of respondents on the DUT/MUT brands, this section compares the two Universities using the Independent T-Test. Table 7 displays the mean, standard deviation, and Independent T-Test results for the two Universities' scoring patterns. The proof is provided that MUT respondents MUT respondents agreed significantly more $(3.74 \pm 0.80)$ when compared against $(3.61 \pm 0.49)$ the DUT counterpart $(P<0.05)$. This implies that MUT respondents were more positive about their University's brand than DUT respondents were.

Table 7

Independent t-test comparison of brand awareness between DUT and MUT

\begin{tabular}{ccccccc}
\hline Comparison & University & N & Mean & Std. Deviation & Std. Error Mean & P-value \\
\hline \multirow{2}{*}{ DUT/MUT brand } & DUT & 296 & 3.6054 & 0.80085 & 0.04655 & 0.015
\end{tabular}

Respondents learned about the DUT/MUT through a variety of channels, including social and mainstream media. Word-of-mouth, as well as family and friends, was more essential and prominent among these sources. As a result, it was vital to know if they would recommend the DUT/MUT to anyone interested in studying at the UoT. As per Fig. 3, the majority of DUT (78.7 \%) and MUT (82.8 \%) respondents said they would promote the brand to other interested potential students. On the other hand, only $17.9 \%$ (DUT) and $8.8 \%$ (MUT) said they would not suggest the brand to other students.

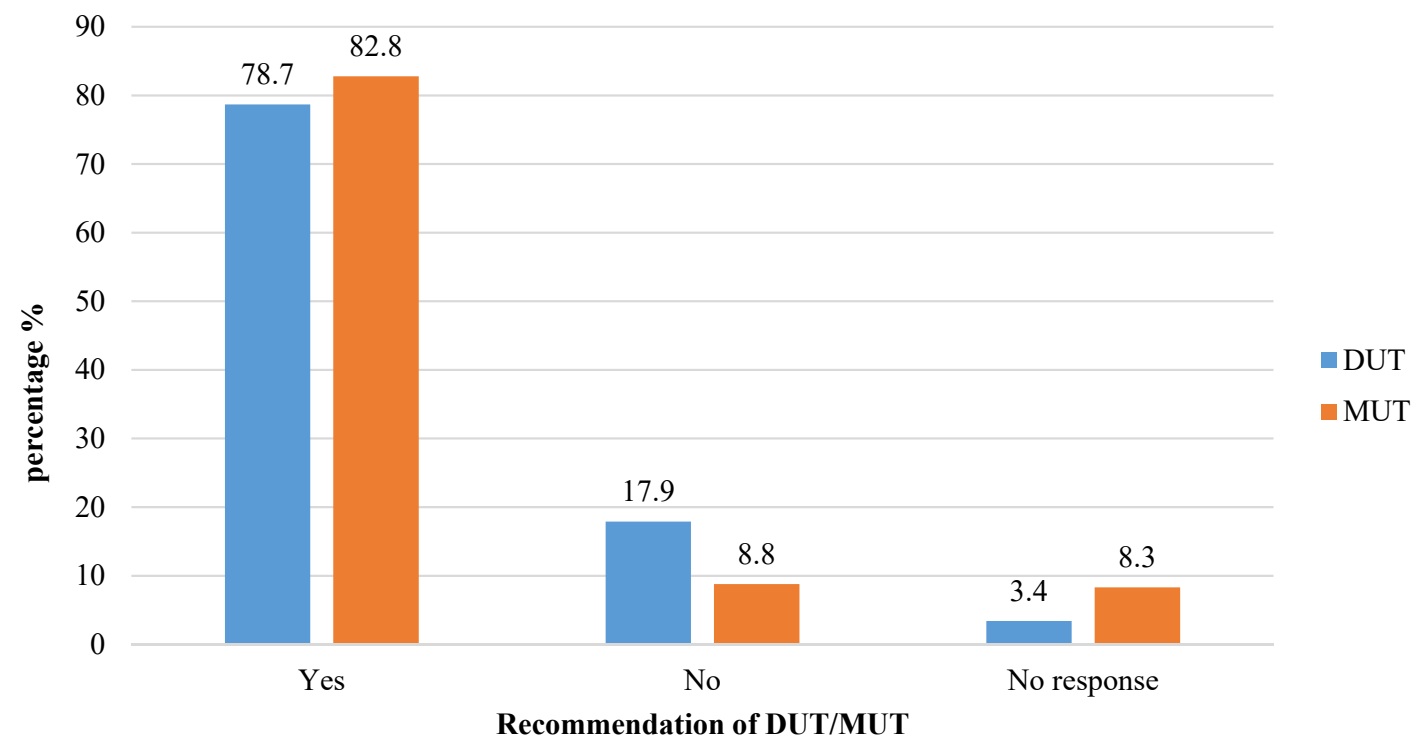

Fig. 3. Recommendation of DUT/MUT brand to potential students 


\section{Discussion}

A large proportion of MUT participants expressed unhappiness with certain of their institution's services. According to the study, both DUT and MUT students believe that most of the brand image qualities influence their choice of a UoT. Although few publications directly address higher education branding in the literature, there is a well-established literature on higher education marketing [25]. The report argues for DUT and MUT to make targeted investments in brand awareness efforts and brand image. This advice is given because effective tailor-made investments in brand awareness campaigns and brand image will attract high-caliber students to these institutions of learning, as well as international students from the African continent and beyond. International students will contribute to the survival and viability of these institutions because they pay a significantly greater tuition charge than local students [26].

Limitations of the study. The survey was confined to first-year students at KwaZulu-Natal universities of technology, rather than all students at the selected universities. Owing to these constraints, the study's findings should not be extrapolated outside this location and the target group.

Prospects for future research. For future research, comparable studies with high school students and second-year students are recommended to ascertain if the findings will remain identical. Similar research might be undertaken to assess the similarities and differences between UoTs and traditional universities, and the study could be expanded to include students from South Africa as well as other African countries. Further research could also be conducted to determine whether South African HEIs are concerned with brand influence and social media usage among their target students.

\section{Conclusion}

Owing to the substantial amount of students from rural populations at DUT and MUT, it is advised, that the Corporate Affairs Units at both institutions conduct awareness campaigns in rural high schools. Such awareness campaigns could describe the many courses, offered at these schools, as well as generate brand awareness campaigns and create a positive image among school students.

This study is significant because it will provide critical insights into the factors that influence students' decision to attend a Higher Education Institution. This study will also be useful in establishing the impact of brand awareness and the role of brand image in first-year students' choice of a UoT. Furthermore, the study primarily assists the institutions (DUT and MUT) in gaining a knowledge of the characteristics that contributed to students' selection of specific Universities. The study is important because it fills gaps in the existing literature on South African UoTs.

\section{Acknowledgments}

The authors acknowledge Dr. D Veerasamy, the study's promoter, as well as the data collectors and students from KwaZulu Natal's two universities of technology, for their involvement and valuable contributions.

\section{References}

[1] Duffett, R. G. (2017). Influence of social media marketing communications on young consumers' attitudes. Young Consumers, 18 (1), 19-39. doi: http://doi.org/10.1108/yc-07-2016-00622

[2] Gunduz, U., Pembecioglu, N. (2015). The role of social media in the sharing and delivery of authoritative and governmental issues. European Journal of Research on Education. Special Issue: Contemporary Studies in Social Science, 24-40.

[3] Royo-Vela, M., Hünermund, U. (2016). Effects of inbound marketing communications on HEIs' brand equity: the mediating role of the student's decision-making process. An exploratory research. Journal of Marketing for Higher Education, 26 (2), 143-167. doi: http://doi.org/10.1080/08841241.2016.1233165

[4] Sebola, M. P. (2015). Local government administration in post-Apartheid South Africa: Some critical perspectives. Batalea Publishers (Pty) Ltd., 18.

[5] Elkevizth, B. H. (2012). From "Education Beyond Utility "to Utility for Legitimacy: Contemporary Opposition to Article 9 Revision in the Context of the Sōka Gakkai's Historical Development. Duke University.

[6] Van der Waldt, G. (2015). Government interventionism and sustainable development: The case of South Africa. African Journal of Public Affairs, 8 (3), 35-50. 
[7] Iwu, C. G., Ezeuduji, I. O., Eresia-Eke, C., Tengeh, R. (2016). The Entrepreneurial Intention of University Students: The Case of a University of Technology in South Africa. Acta Universitatis Danubius. OEconomica, 12 (1), 164-181.

[8] Department of Higher Education and Training (DHET) (2017). Statistics on Post School Education and Training in South Africa: 2015. Available at: https://www.dhet.gov.za/DHET\%20Statistics\%20Publication/Statistics\%20on\%20Post-School\%20 Education\%20and\%20Training\%20in\%20South\%20Africa\%202015.pdf Last accessed: 31.05 .2020

[9] Ho, S. S. H. (2017). The impact of Taiwanese college students' learning motivation from self-determination perspective on learning outcomes: Moderating roles of multi-traits. Educational Sciences: Theory \& Practice, 17, 1015-1034. doi: http:// doi.org/10.12738/estp.2017.3.0406

[10] Yakup, D. (2011). A theoretical approach to concept of green marketing assist. Interdisciplinary Journal of Contemporary Research in Business, 3 (2), 1808-1814.

[11] Pimpa, N., Suwannapirom, S. (2007). Thai students' choices of vocational education: marketing factors and reference groups. Educational Research for Policy and Practice, 7 (2), 99-107. doi: http://doi.org/10.1007/s10671-007-9035-9

[12] Tavares, D., Tavares, O., Justino, E., Amaral, A. (2008). Students' preferences and needs in Portuguese higher education. European Journal of Education, 43 (1), 107-122. doi: http://doi.org/10.1111/j.1465-3435.2007.00331.x

[13] Hollensen, S. (2019). Marketing management: A relationship approach. Pearson UK.

[14] Lowrie, T. (2014). Rural and remote mathematics education. Encyclopedia of mathematics education. Springer, 532-534. doi: http://doi.org/10.1007/978-94-007-4978-8_135

[15] Khare, A., Parveen, C., Rai, R. (2010). Retailer behavior as determinant of service quality in Indian retailing. Journal of Retail \& Leisure Property, 9 (4), 303-317. doi: http://doi.org/10.1057/rlp.2010.14

[16] Das, A., Kumar, V., Saha, G. C. (2010). Retail service quality in context of CIS countries. International Journal of Quality \& Reliability Management, 27 (6), 658-683. doi: http://doi.org/10.1108/02656711011054542

[17] Zaim, H., Bayyurt, N., Zaim, S. (2010). Service quality and determinants of customer satisfaction in hospitals: Turkish experience. International Business \& Economics Research Journal (IBER), 9 (5), 51-58. doi: http://doi.org/10.19030/iber.v9i5.8145

[18] Siddiqi, K. O. (2011). Interrelations between service quality attributes, customer satisfaction and customer loyalty in the retail banking sector in Bangladesh. International journal of business and management, 6 (3), 12-36. doi: http://doi.org/10.5539/ ijbm.v6n3p12

[19] Wong, A., Sohal, A. (2003). Service quality and customer loyalty perspectives on two levels of retail relationships. Journal of Services Marketing, 17 (5), 495-513. doi: http://doi.org/10.1108/08876040310486285

[20] Ashraf, M., Naeem, M., Shahzadi, M. (2017). Impact of Branding on Consumer Buying Behavior: An Evidence of Footwear Industry of Punjab, Pakistan. International Journal of Academic Research in Business and Social Sciences, 7 (7), 592-603. doi: http://doi.org/10.6007/ijarbss/v7-i7/3124

[21] Kotler, P., Amstrong, G. (2011). Principles of marketing. 9th ed. Harlow: Pearson.

[22] Raposo, M., Alves, H. (2007). A model of university choice: an exploratory approach. Available at: https://mpra.ub.unimuenchen.de/5523/ Last accessed: 14.08.2021

[23] Sekaran, U., Bougie, R. (2019). Research methods for business: A skill building approach. John Wiley \& Sons.

[24] Bowling, A. (2005). Mode of questionnaire administration can have serious effects on data quality. Journal of Public Health, 27 (3), 281-291. doi: http://doi.org/10.1093/pubmed/fdi031

[25] Hemsley-Brown, J., Oplatka, I. (2015). University choice: what do we know, what don't we know and what do we still need to find out? International Journal of Educational Management, 29 (3), 254-274. doi: http://doi.org/10.1108/ijem-10-2013-0150

[26] Durban University of Technology (DUT) webpage 2019. Available at: https://www.dut.ac.za/

Received date 24.09.2021

Accepted date 22.11.2021

Published date 30.11.2021
(C) The Author(s) 2021

This is an open access article under the Creative Commons CC BY license

How to cite: Matli, C. M., Tlapana, T., Hawkins-Mofokeng, R. (2021). The influence of brand image on the selection and preference of universities of technology. EUREKA: Social and Humanities, 6, 3-13. doi: http://doi.org/10.21303/2504-5571.2021.002065 